\title{
Ring Opening of a meso-Azabicyclic Alkene with an Arylboronic Acid
}

Metal-Catalyzed Asymmetric Synthesis and Stereoselective

Reactions

\section{Key words}

palladium

asymmetric ring opening

arylboronic acids

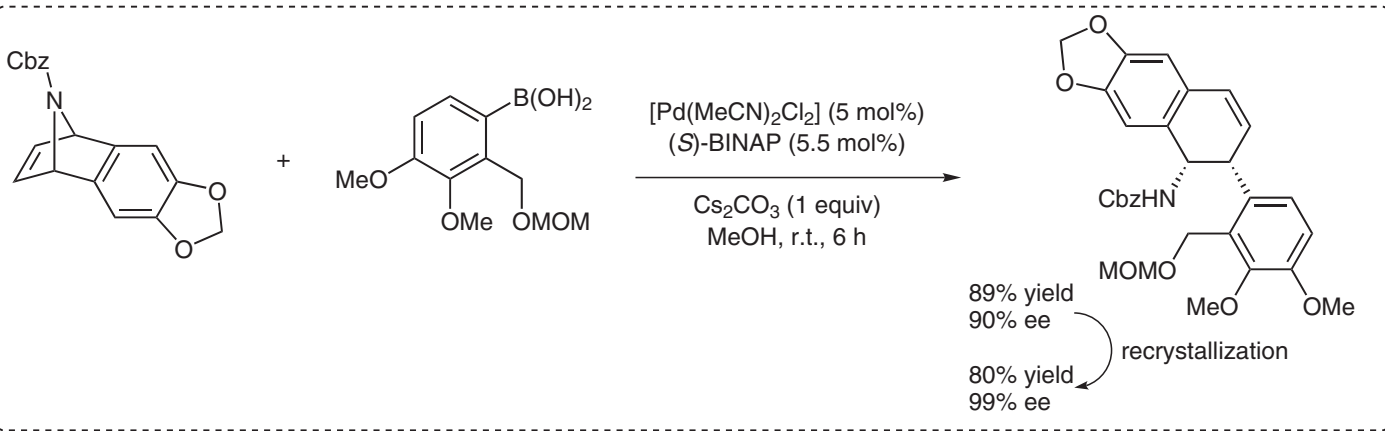<smiles>C1=Cc2cc3c(cc2CC1)OCO3</smiles>

CbzHN<smiles>CCc1c2ccc(OC)c1OCCC2</smiles>
\section{$\underset{i-\mathrm{PrOH}-\mathrm{THF}}{\stackrel{\mathrm{HCl}}{\longrightarrow}}$}<smiles>C1=Cc2cc3c(cc2CC1)OCO3</smiles>
CbzHN<smiles>COc1cccc(CO)c1OC</smiles>
$\mathrm{CBr}_{4}, \mathrm{PPh}_{3}$ then $\mathrm{NaH}$

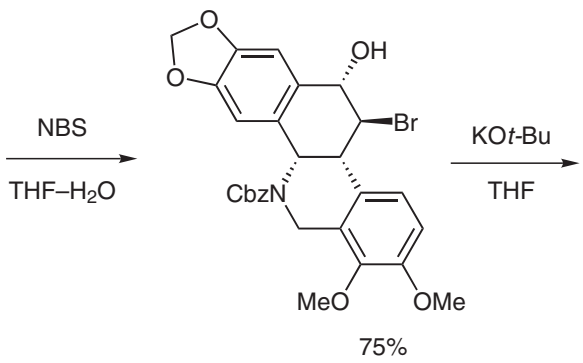

$75 \%$

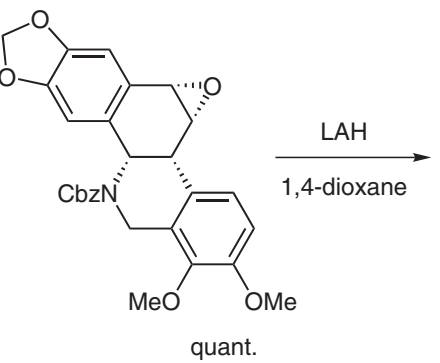

quant.
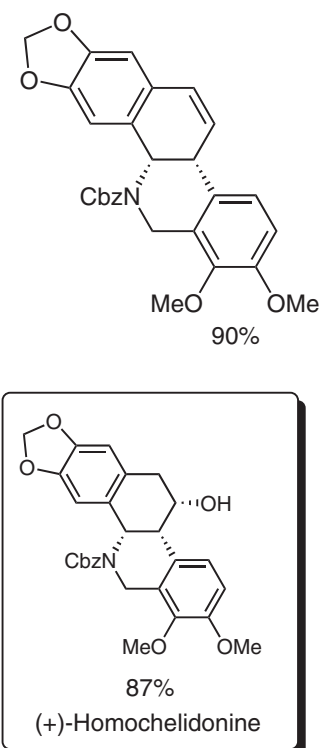

Significance: The first enantioselective total synthesis of the biologically important (+)-homochelidonine was accomplished utilizing an excellent desymmetrization of a meso-bicylic alkene based on a palladium-catalyzed ring-opening reaction. This method creates two contiguous syn stereocenters from readily available meso compounds. Once this chirality is installed, subsequent diastereoselective bromohydrin formation leading to an epoxide is expertly accomplished.
Comment: The Lautens group has further utilized their ring-opening reactions to include an asymmetric variant for the addition of arylboronic acid nucleophiles. While they had previously reported the racemic version of this reaction (M. Lautens, C. Dockendorff Org. Lett. 2003, 5, 3695-3698) they show here that (S)-BINAP is a good ligand for this transformation. Importantly, arylboronic acids are now added to the list of nucleophiles suitable for this type of ring-opening reaction. 